\title{
The activity of the murine Bax promoter is regulated by Sp1/3 and E-box binding proteins but not by $\mathrm{p} 53$
}

\author{
Thorsten Schmidt ${ }^{1,4}$, Kathrin Körner ${ }^{3,4}$, Holger Karsunky ${ }^{1}$, \\ Stanley Korsmeyer ${ }^{2}$, Rolf Müller ${ }^{3}$ and Tarik Möröy, ${ }^{\star 1}$ \\ 1 Institut für Zellbiologie (Tumorforschung), I F Z, Universitätsklinikum Essen, \\ Virchowstrasse 173, Germany \\ 2 Dana Farber Cancer Institute, Dept of Cancer Immunology and AIDS 1, \\ Jimmy Fund Way, Boston, Massachusetts, MA 02115, USA \\ ${ }^{3}$ Institut für Molekularbiologie und Tumorforschung, Philipps Universität \\ Marburg, Emil-Mannkopff-Strasse 2, D-35033 Marburg, Germany \\ 4 These authors contributed equally to this work \\ * corresponding author: Institut für Zellbiologie (Tumorforschung), I F Z, \\ Universitätsklinikum Essen, Virchowstrasse 173, D-45122 Essen, Germany, \\ tel.: 49 (201) 723 - 3380, fax: 49 (201) 723 -5904; \\ e-mail: moeroey@uni-essen.de
}

Received 6.3.99; revised 6.7.99; accepted 9.7.99

Edited by G. Melino

\begin{abstract}
In human cells the expression of the pro-apoptotic protein Bax appears to be regulated through p53-dependent transcriptional activation. However, in the mouse, p53-deficiency does not affect Bax expression. To shed more light on the transcriptional regulation of the bax gene we have analyzed the murine bax promoter. We find several E-box and Sp1/Sp3 binding sites as well as three putative $p 53$ binding sites that are conserved in the human promoter sequence. We can show that both the Sp1 and the E-box binding sites are necessary for proper regulation of bax transcription and show by genomic DMS footprinting that all these sites are occupied in vivo. In contrast, the putative $p 53$ binding sites were not occupied by protein in vivo in primary murine thymocytes either before or after induction of p53 by DNA damage. Moreover, p53 was unable to regulate the transcription of bax promoter fragments up to $6.5 \mathrm{~kb}$ in length. Further, steady state levels of bax mRNA did not correlate with Bax protein expression levels in DNA damage-induced cell death. Our findings exclude a direct transcriptional transactivation of the bax gene by $\mathrm{p} 53$ in murine cells suggesting a dominance of p53 independent mechanisms for the regulation of Bax protein expression.
\end{abstract}

Keywords: bax; p53; in vivo footprinting; apoptosis

Abbreviations: PE, prime extension; RACE, rapid amplification of cDNA ends; FACS, fluorescence activated cell sorter; DEAE, diethyl-amino-ethyl

\section{Introduction}

The Bax protein belongs to the Bcl-2 family of programmed cell death regulators which fall into two classes: Inhibitors of apoptosis among them Bcl-2, Bcl- $x_{\mathrm{L}}, \mathrm{Bcl}-\mathrm{w}$, and activators of apoptosis which comprise Bax, Bak, Bcl- $x_{S}$, Bad and others. $^{1-4}$ Many members of this family of proteins share four conserved stretches of sequences that have been termed $\mathrm{BH} 1-\mathrm{BH} 4$ domains. ${ }^{4}$ Three of these domains namely $\mathrm{BH} 1$, $\mathrm{BH} 2$ and $\mathrm{BH} 4$, as well as the carboxy-terminal hydrophobic transmembrane (TM) region (membrane anchor) that is present in most Bcl-2 family members are of critical importance. Bax contains $\mathrm{BH} 1, \mathrm{BH} 2$ and $\mathrm{BH} 3$ domains but probably no $\mathrm{BH} 4$. Bax expression is found in a wide variety of tissues including lymphoid organs, lung, stomach and kidney.

It has been shown that $\gamma$-irradiation can induce an upregulation of Bax protein levels followed by subsequent apoptosis in radiation-sensitive mouse cells as for example thymocytes. ${ }^{5}$ In addition, this induction of Bax expression by DNA damage is preceded by an upregulation of the tumor suppressor protein p53 and in some instances it has been demonstrated that Bax is a downstream effector of p53 in human cells. ${ }^{6}$ On the other hand, many cell types from Bax deficient mice, among them thymocytes, do not show alterations in their p53 dependent DNA damage pathways. ${ }^{7}$ Moreover, transgenic mice with a constitutive expression of Bax show increased apoptosis in certain cell types, in particular lymphocytes. However this constitutive bax expression cannot rescue p53 deficiency in response to DNA damage. ${ }^{8,9}$ Hence, Bax cannot be the sole apoptotic effector of p53 in DNA damage-induced apoptosis.

The p53 tumor suppressor protein can function as a transcription factor. Among the well documented biological activities of p53 are the induction of cell cycle arrest either in $\mathrm{G} 1$ or $\mathrm{G} 2$ and the induction of apoptosis, both effects being induced upon DNA damage. ${ }^{10-14}$ Expression levels of p53 are induced after DNA damage probably through stabilization of the protein. The induction of $\mathrm{G} 1$ arrest by p53 appears to be mediated of one direct downstream target of $\mathrm{p53}$, the cyclin dependent kinase inhibitor p21 WAF ${ }^{15-17}$ How p53 induces programmed cell death when DNA damage occurs remains to be fully elucidated but seems to involve transcriptional transactivation of particular target genes but also other mechanisms. ${ }^{18,19}$ In human cells, Bax has been shown to be transcriptionally activated by 053 after DNA damage. ${ }^{6}$ However, this might not be the case in general as the situation is different in other cell types in particular in murine cells where Bax appears to contribute only in part to p53-mediated cell death: ${ }^{2,20}$ For instance, the pro-apoptotic function of p53 is not in any way affected in Bax-deficient mice and apoptosis in transgenic Bax expressing thymocytes is neither increased nor accelerated in a p53 null background.

To determine the connection between p53 and Bax during DNA damage-induced apoptosis in murine cells, we have characterized the mouse Bax promoter by genomic DMS footprinting and reporter gene assays. We present evidence that at least in murine thymocytes and fibroblasts the induction of Bax expression after DNA damage is regulated 
on the transcriptional level by the transcription factors Sp1 and so far unknown E-box binding proteins, but not by p53.

\section{Results \\ Identification of the region of transcription initiation in the murine bax gene}

To analyze the transcriptional regulation of the murine bax gene we subcloned a $6.5 \mathrm{~kb}$ genomic fragment and determined the DNA sequence of the first 900 base pairs upstream of the translation initiation site (Figure 1). A sequence comparison between the human ${ }^{6}$ and the murine $5^{\prime}$-untranslated region of the bax gene revealed strong homologies in the region between -1 and -132 relative to the initiator ATG. Primer extension (PE) analysis revealed that several transcription initiation sites are clustered between -26 and -69 (Figure 1) which would be in agreement with the lack of a typical TATA-box like sequence in this promoter. By $5^{\prime}$-RACE - PCR we could verify that the data obtained by primer extension analysis indeed correspond to known cDNA ends in this transcriptionally active region, because most of the signals obtained with PE and RACE - PCR were found to be identical and others were located in close proximity to each other (Figure 1). Furthermore, we could identify several potential transcription factor binding sites by sequence comparison. Three sites corresponded to E-boxes (E-box I-III) and were located between -54 and -132 , three other sequence elements were homologous to Sp1-motives (Sp1/ $\mathrm{I}-/ \mathrm{III})$ and were located at -108 to $-114,-153$ to -159 and -235 to -241 , respectively. Further upstream sequences (between position -303 to -339 ) were found to harbor strong homology to p53 binding-sites (Figure 1).

\section{Identification of protein binding sites in the bax promoter region}

To identify which of the potential binding sites identified by sequence homology are involved in the transcriptional regulation of the murine bax gene, we first analyzed the occupation of the bax promoter sequence by proteins in these regions using genomic in vivo DMS footprinting. Four distinct protected areas on the non-coding strand were found in normally growing NIH3T3 cells within the bax promoter region between position -44 and -163 (Figure 2). The occupied areas corresponded to the previously suspected E-box and Sp1/I binding site (Figures 1 and 2). The G-residues in the core 'CACGTG' elements of E-box I, II and III (Figure 1) were protected as well as one $G$ in the immediate flanking region of E-boxes I and III (Figure 2). Further protections were observed at the putative Sp1 site II $(-152$ to -155 and -157) whereas no protection was obtained for the suspected Sp1 site I (Figure 2) potentially because most of the G residues of this particular site are located on the coding strand (Figure 2). Since it had been reported previously that the bax gene is transcriptionally induced after the induction of apoptosis by different apoptotic stimuli, we performed the same analysis with murine thymocytes which are highly sensitive to apoptotic processes mediated by steroids or DNA damage. However, the same protection pattern as for NIH3T3 cells was obtained by DMS footprinting within the analyzed area (data not shown).

\section{Correlation of protein-binding in vivo and transcriptional activity of the bax promoter}

To explore the functional significance of the protected protein binding sites identified by footprinting, we constructed different reporter genes by inserting DNA fragments of the bax promoter comprising sequences until position -6500 relative to the ATG initiator codon (Figure 3) into a promoterless plasmid containing the luciferase gene ( $p G L 3$, Figure 3). With these constructs, we performed transient transfections in NIH3T3 cells (Figure 3) and El-4 Tlymphocytes (data not shown). 5'-deletions of a $6.5 \mathrm{~kb}$ promoter fragment (Figure 3a) up to position -382 led to a 15 -fold increase in promoter activity, which is probably due to the loss of unidentified silencer elements in this region. It has been reported that the T-cell specific transcriptional repressor Gfi-1 is involved in the transcriptional repression

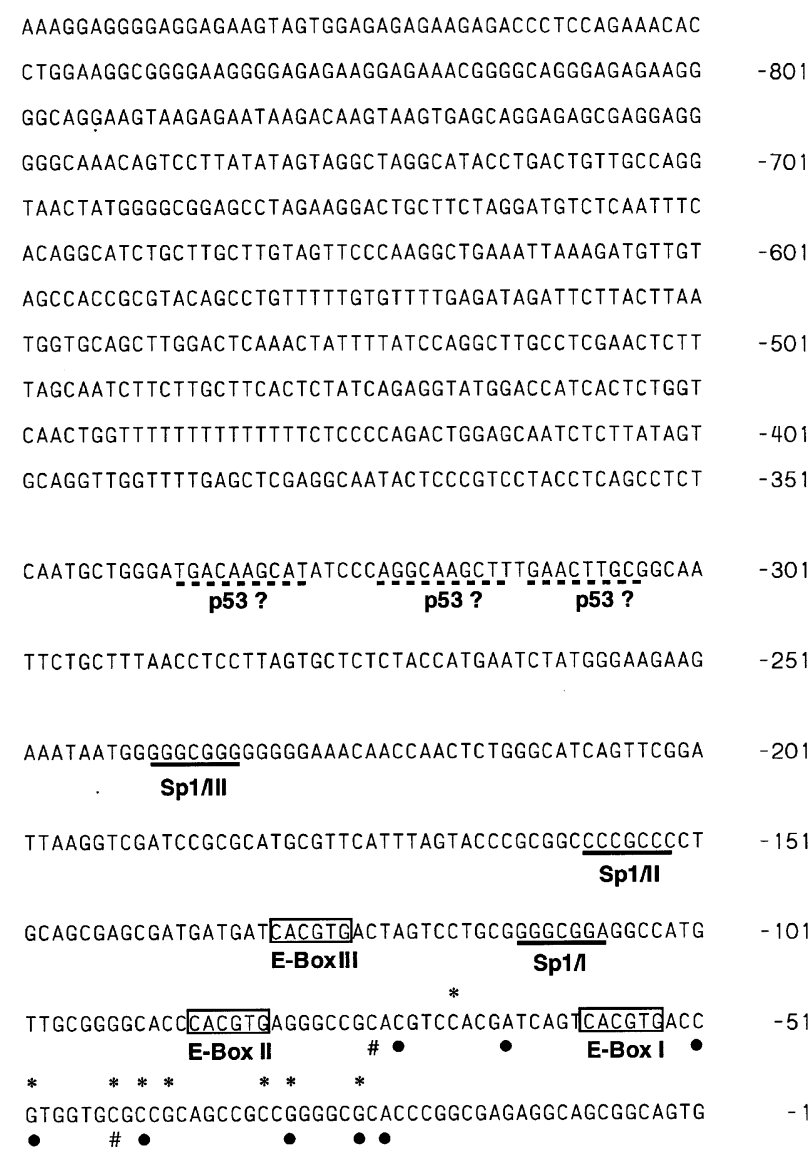

Figure 1 Nucleotide sequence of the murine bax promoter and upstream region. The nucleotide sequence of the murine bax promoter corresponding to the first 900 nucleotides upstream of the translation initiation site is shown. Transcription start sites of the TATA/Inr less bax promoter are indicated by $(\mathbf{0})$ for sites mapped by primer extension and $\left(^{*}\right)$ for sites mapped by $5^{\prime}$-RACE PCR. Published murine bax cDNA $5^{\prime}$ ends are marked by (\#). The CACGTG EBox protein binding motifs (E-Box $\mathrm{I}-\mathrm{III}$ ) are boxed and sequences homologous to the Sp1/Sp3 consensus binding site (Sp1/I-III) are underlined. Potential p53 binding sites are underlined with a broken line 
of the human bax promoter. ${ }^{21}$ However, cotransfections of Gfi-1 expression plasmids with the $6.5 \mathrm{~kb}$ or the $2.6 \mathrm{~kb}$ bax promoter constructs (Figure 3 ) in NIH3T3 or EL-4 T cells did not reveal any effect of Gfi-1 on the activity of the murine bax promoter in contrast to positive controls (data not shown). Further $5^{\prime}$ truncations of the -382 construct led to a decrease of promoter activity (Figure $3 b$ ) suggesting that this region contains important sites for promoter activation. Indeed, when the putative Sp1 sites or the suspected Eboxes were deleted (either $5^{\prime}, 3^{\prime}$ or internal, Figure 3b,c) or mutated (not shown) a strong loss of promoter activity for each of these sites was observed (Figure 3b,c). This suggested again that all three E-boxes and the putative Sp1 binding sites are implicated in the transcriptional activation of the murine bax promoter in normally growing fibroblasts and T-lymphocytes.

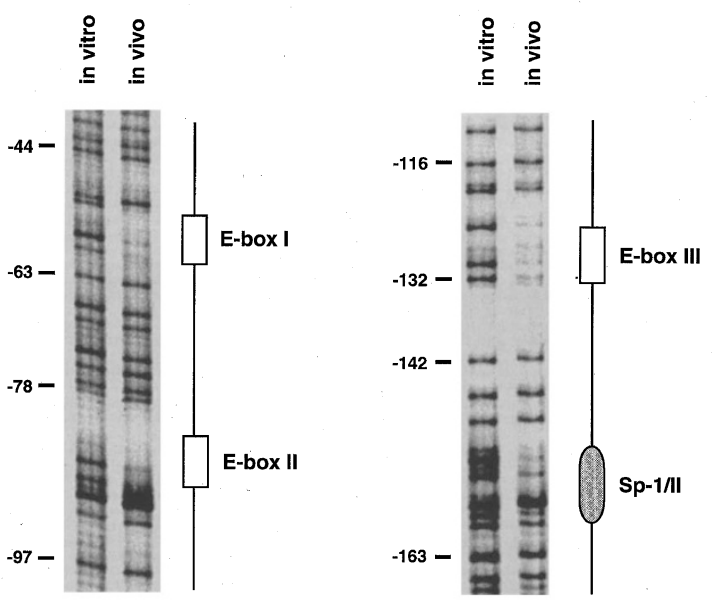

b

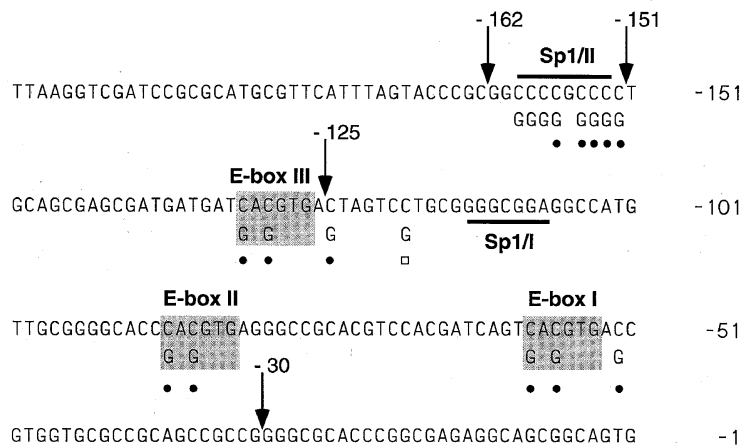

Figure 2 Identification of protein binding sites in the murine bax promoter by in vivo DMS footprinting. The non-coding strand of the murine bax promoter in the region spanning the nucleotides from position -170 and +1 relative to the initiator ATG was analyzed by genomic DMS footprinting in NIH3T3 cells. (a) Four constitutively protected areas could be detected which are protected in NIH3T3 cells, thymocytes and p53-deficient cells under normal growth conditions as well as after treatment with dexamethasone $(2 \mu \mathrm{M})$ or etoposide $(50 \mu \mathrm{M})$ (data not shown). The identified protein-binding regions are shown in (b) with the protected G-residues marked by filled circles for full constitutive protections and open squares to denote conditional protections in thymocytes

\section{Interation of Sp1/3 with sequences in the murine bax promoter}

To identify the proteins binding to the three Sp1 elements in the murine bax promoter we performed electrophoretic mobility shift assays (EMSA) with radiolabeled oligonucleotides comprising the putative Sp1 elements I-III and nuclear extracts from normally growing NIH3T3 cells (Figure 4). All probes could form protein-DNA complexes containing Sp1 and $\mathrm{Sp} 3$ as identified by competition with a bona fide Sp1/3 element (GT-box) or supershift experiments (Figure 4) using polyclonal anti-Sp1 and anti-Sp3 antibodies. ${ }^{22}$ Together with the deletional analysis and footprinting results, these data suggest that $\mathrm{Sp} 1 / 3$ acts as a transcriptional activator of the bax promoter. In a similar approach we tried to identify the protein complexes binding to the E-boxes in vivo (Figure 2), however neither EMSAs (data not shown) nor co-transfections of the murine bax promoter with typical E-box binding proteins (Myc and Max, USF, TFE III) and bax-mRNA analysis of inducible Myc-ER Rat-1 fibroblasts ${ }^{23}$ led to positive results (data not shown). Therefore, the identity of the proteins binding to the E-boxes in vivo and activating the bax promoter as shown in Figures 2 and 3 still remains to be determined.

\section{p53 does not transcriptionally activate the murine bax promoter}

Previous reports showed that Bax expression is induced in different cell types and tissues in a p53-dependent manner. ${ }^{5,24,25}$ Moreover, the human bax promoter has been reported to be transcriptionally activated by $053 .{ }^{6}$ Thus, we analyzed the effect of p53 induction on the transcriptional activity of the murine bax promoter. First, comparison between the murine bax gene and several p53 binding sites from various promoters revealed indeed strong sequence similarities of a region between position -303 and -339 of the bax promoter to reported p53 binding sites (Figure 5a). To test the functional relevance of these putative p53 binding sites, we performed co-transfection experiments in different p53-deficient cell lines (Saos-2, Hela, Figure $5 \mathrm{~b}$ ). As a positive control we used a reporter gene construct containing the p53 responsive part of the mdm-2 promoter. ${ }^{26}$ This reporter showed a 5-9-fold increase in luciferase activity after exogenous expression of wild-type p53 whereas a mutant p53 (p53 M-175), ${ }^{27}$ did not lead to detectable changes in mdm-2 promoter activity (Figure $5 b$ ). In contrast, the bax c2675 promoter construct (see Figure 3b) could not be induced at all by exogenous expression of wild-type human p53 either in Saos-2 or HeLa cells (Figure 5b). Similar results were obtained in experiments with murine NIH3T3 cells and EL-4 T-cells and also for the longer $6.5 \mathrm{~kb}$ bax reporter construct (data not shown). In addition, in murine EL-4 T-cells etoposide-induced induction of endogenous p53 did not activate the murine bax promotor constructs either which indicates that the lack of transcriptional activation of the bax c2675 promotor construct is not due to species specific differences between murine and human p53 (data not shown).

Moreover, no occupation of the putative p53 binding sites could be detected in the murine bax promoter by genomic in vivo DMS footprinting of etoposide-treated and 
untreated primary thymocytes (Figure 5c) although p53 was clearly induced by the treatment (Figure 6a). Taken together, these data strongly suggest that in the analyzed murine cells the putative p53 binding sites are not occupied

a

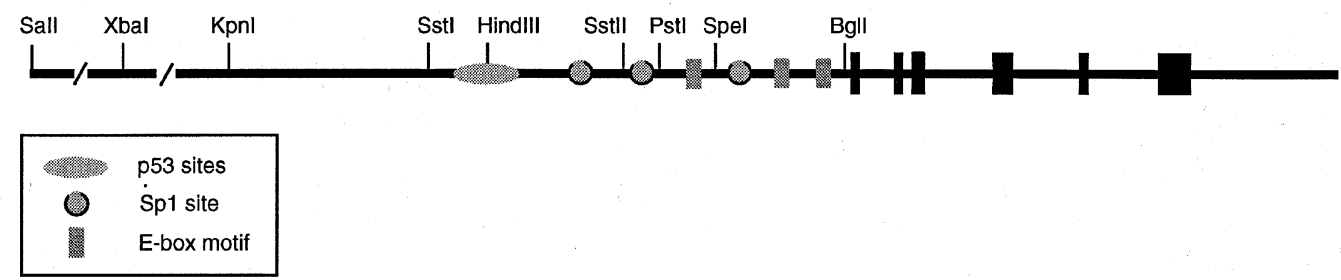

b

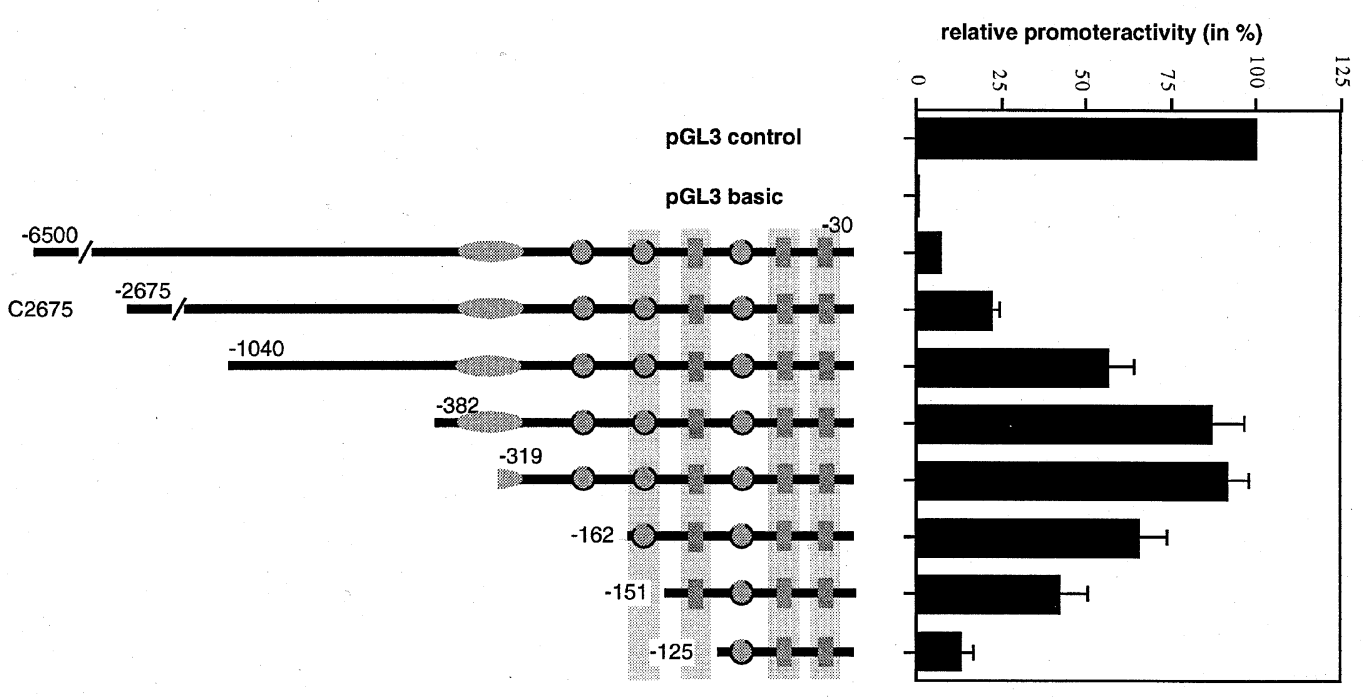

C

C1040
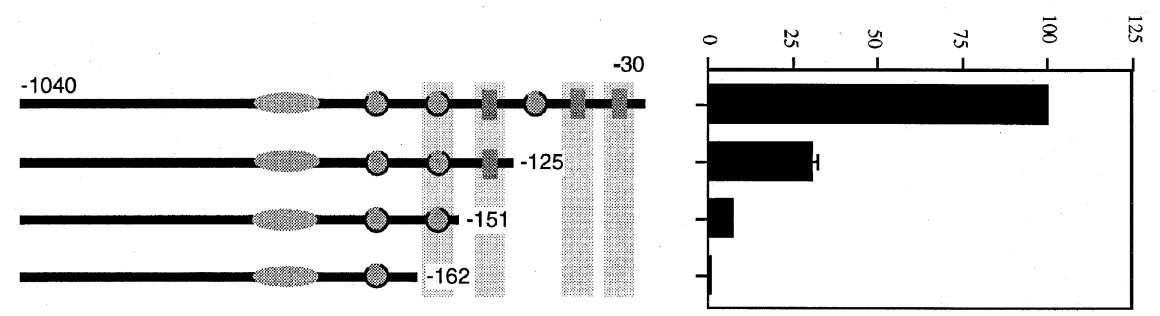

d
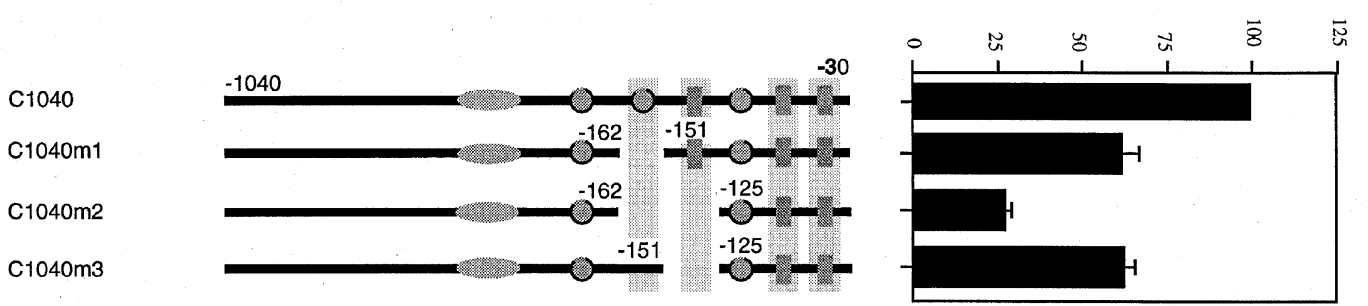

Figure 3 Transient transfections with deletion mutants of the murine bax promoter. (a) Schematic representation of the genomic structure of the entire murine bax gene (a). Coding sequences (Exon I- $\mathrm{VI}$ ) are marked with black boxes. Major restriction sites used for cloning of promoter fragments into luciferase constructs are indicated. The Sp1, E-box and p53 binding motifs are represented by grey circles and boxes. (b-d) Transient expression analysis of $5^{\prime}$ and $3^{\prime}$ truncated or internally deleted (C1040m1-3) bax promoter-luciferase constructs in NIH3T3 cells. Various fragments of the murine bax promoter were subcloned into the pGL3 basic luciferase plasmid and transfected into NIH3T3 cells by the DEAE method. Results of transient luciferase assays (RLU) are shown in per cent (\%) relative to the pGL3 Control vector (b) or the C1040 wild-type construct (c,d). Each construct was assayed 3-6 times each time in triplicates using at least two independent preparations of plasmid DNA. Given are mean values with standard deviations from representative experiments 
in the major groove in vivo and that in the analyzed cell systems p53 expression does not have any effect on the transcriptional activity of the murine bax promoter within $6.5 \mathrm{~kb} 5^{\prime}$ of the transcriptional start site.

\section{Lack of regulation of Bax expression by $\mathrm{p} 53$}

Our data make a direct transcriptional activation of bax by p53 very unlikely at least in murine cells. However, induction of apoptosis by DNA damage correlated in thymocytes with a slight induction of Bax protein expression in p53 wt thymocytes (about twofold) but not in p53 deficient cells (Figure 6a). In contrast, induction of apoptosis by steroids as dexamethasone leaves Bax protein expression independently of p53 status at the level of untreated cells (Figure 6a). Thus, we aimed to clarify how and to what degree p53 may induce Bax protein expression in thymocytes upon DNA damage or in the presence of steroids without affecting the transcriptional activity of the bax promoter. To this end, we performed a detailed analysis of the described bax transcripts ${ }^{28}$ in wildtype and p53-deficient thymocytes upon treatment with etoposide and dexamethasone. Northern blot analysis demonstrated that etoposide treatment results in downregulation of the $1.0 \mathrm{~kb}$ bax transcripts and in upregulation of the 1.5 bax mRNA subtypes and of another $1.8 \mathrm{~kb}$ bax
mRNA species in wild-type but not p53 null thymocytes (Figure $6 \mathrm{~b}$ ). In contrast, a $3 \mathrm{~h}$ treatment with dexamethasone led to a clear downregulation of both 1.0 and $1.5 \mathrm{~kb}$ bax mRNA levels in both wild-type or p53 null thymocytes (Figure $6 b)$.

Quantification of mRNA levels by phosphoimager scanning again demonstrated the decrease in expression level for the $1.0 \mathrm{~kb}$ bax mRNA transcripts and an increase of the 1.5 and $1.8 \mathrm{~kb}$ bax mRNA species within $3 \mathrm{~h}$ of etoposide treatment (Figure 6b,c). In agreement with previous results this represents only a small overall increase (from 100-130\%) of total bax mRNA after induction of apoptosis by DNA damage (Figure 6d). Remarkably, in the absence of p53, the steady state level of the 1.0 and $1.5 \mathrm{~kb}$ bax transcripts persists and does not change in thymocytes upon DNA damage induced by etoposide (Figure 6b). In contrast, dexamethasone treatment downregulates both 1.0 and 1.5 bax mRNA expression levels also in p53 deficient thymocytes (Figure $6 \mathrm{~b})$. As an additional control, we performed 5' RACE - PCR with RNA from control thymocytes and etoposide treated thymocytes and could confirm that the $5^{\prime}$ mRNA start sites remain unaffected by the etoposide treatment (data not shown) indicating that indeed all three bax mRNA subspecies depicted in Figure $6 b$ are generated by

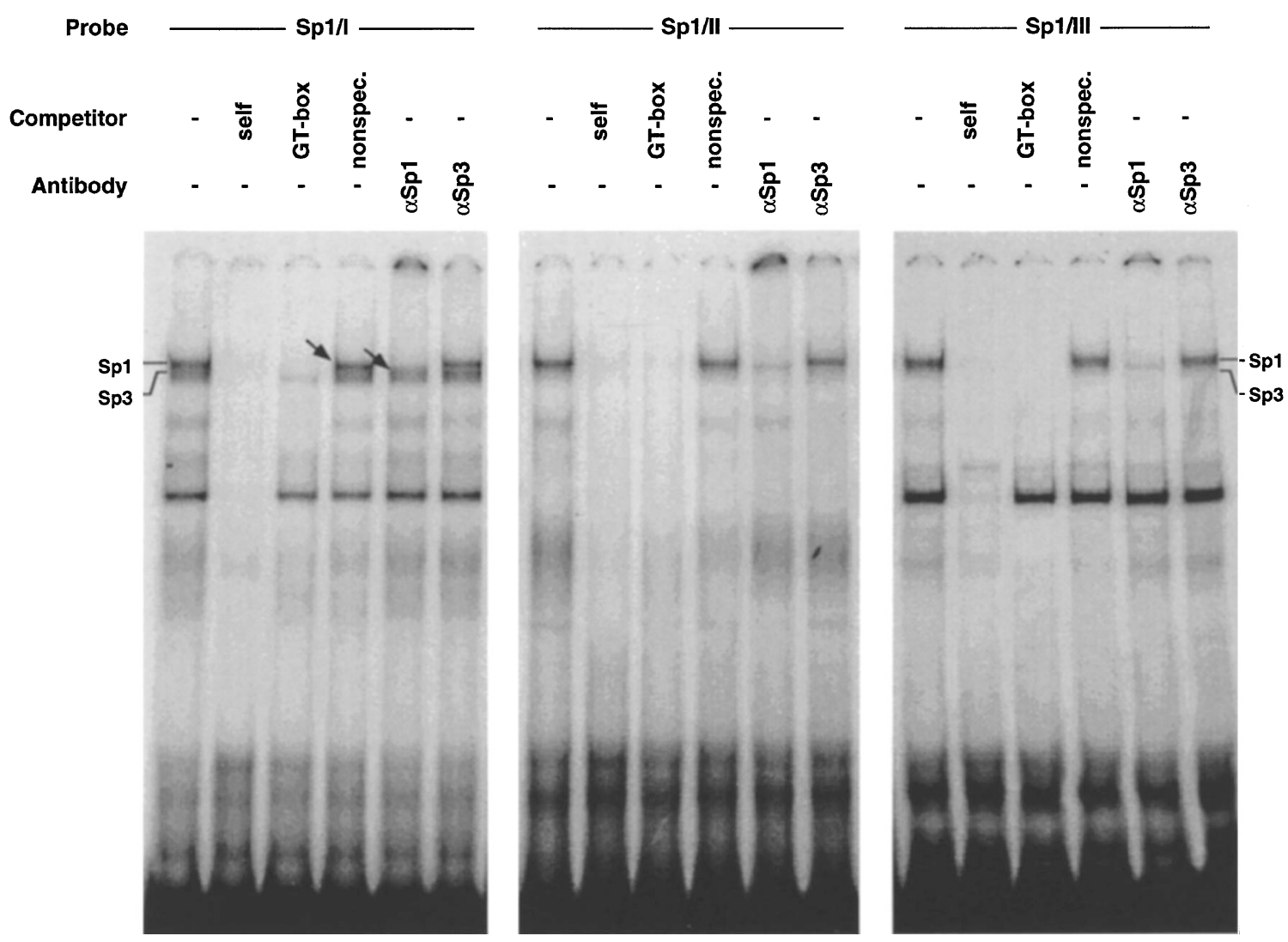

Figure 4 Binding of Sp1 and Sp3 to the Sp1 binding motifs in the murine bax promoter. Electrophoretic mobility shift analysis (EMSA) of protein complexes interacting with the Sp1/I, Sp1/II and Sp1/III binding sites in the absence and presence of specific (self-competition, Sp1/3 binding GT-box) and nonspecific competitors (100-fold excess over probe). For antibody supershift analysis polyclonal antibodies raised against Sp1 and Sp3 ${ }^{22}$ were used. An unrelated polyclonal antibody (IgG) was used as a control and did not affect complex formation (data not shown). Sp1 and Sp3 specific bands are marked by arrows 
alternative splicing as described ${ }^{28}$ and not by alternative transcription initiation sites.

Despite the clear downregulation of the $1.0 \mathrm{~kb}$ bax mRNA transcripts in normal thymocytes after etoposide treatment (Figure $6 \mathrm{~b}$ ) levels of the corresponding p21 $\alpha \mathrm{Bax}$ protein rise slightly (Figure $6 \mathrm{6}$ ) suggesting a regulatory effect at the post-transcriptional level. In p53 deficient thymocytes, both dexamethasone and etoposide treatment leave the expression of the $21 \mathrm{kD}$ Bax $\alpha$ protein form at about the same level as in untreated cells (Figure 6a). The antibody used in the Western analysis is directed against an $\mathrm{N}$-terminal peptide common to $\operatorname{Bax} \alpha, \beta$ and $\gamma$ forms ${ }^{28}$ but only detects the p21 kD bax $\alpha$ form and not the other forms of $24 \mathrm{kD}$ or $4.5 \mathrm{kD}$ (Figure 6a) suggesting that the $1.5 \mathrm{~kb}$ bax mRNA is not translated very efficiently. Moreover, this indicates that variations in steady state levels of all bax specific transcripts do not reflect protein expression level and suggests that the regulation of Bax protein expression takes place at a post-transcriptional level.

\section{Discussion}

The p53 protein is recognized as a major regulatory factor in DNA damage-induced apoptosis in particular in cells of the lymphoid lineage. ${ }^{10-14}$ A number of downstream effectors have been proposed for p53 action among the proapoptotic protein Bax. In human cells Bax expression appears to be directly regulated by p53 through transcriptional transactivation. ${ }^{6}$ The human bax promoter responds directly to p53 and in vitro p53 can bind to specific DNA sites in the bax promoter. ${ }^{6}$ Mouse models to study the effect of Bax on homeostasis in vivo however laid down a more complicated picture. Bax-deficient mice do not show any disturbances in DNA damage-induced and thereby p53-dependent cell death. ${ }^{7}$ In addition, Bax transgenic mice that overexpress

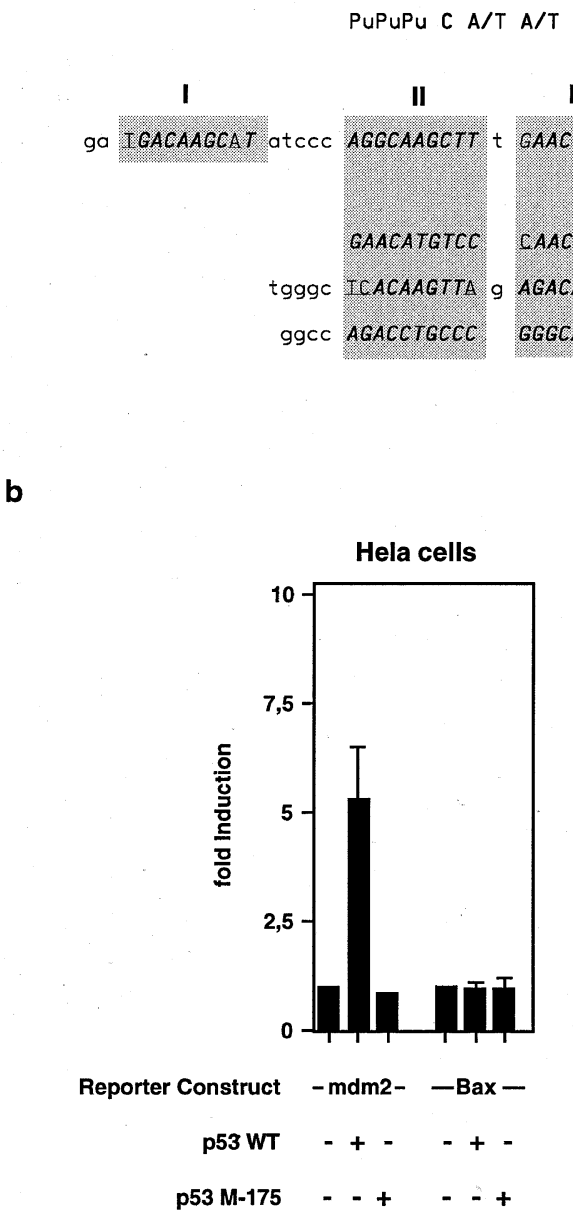

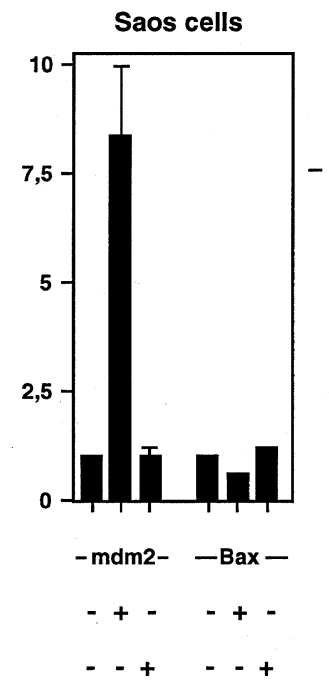

C

p53 consensus

mBAX

WAF1

hBAX

Cyclin G

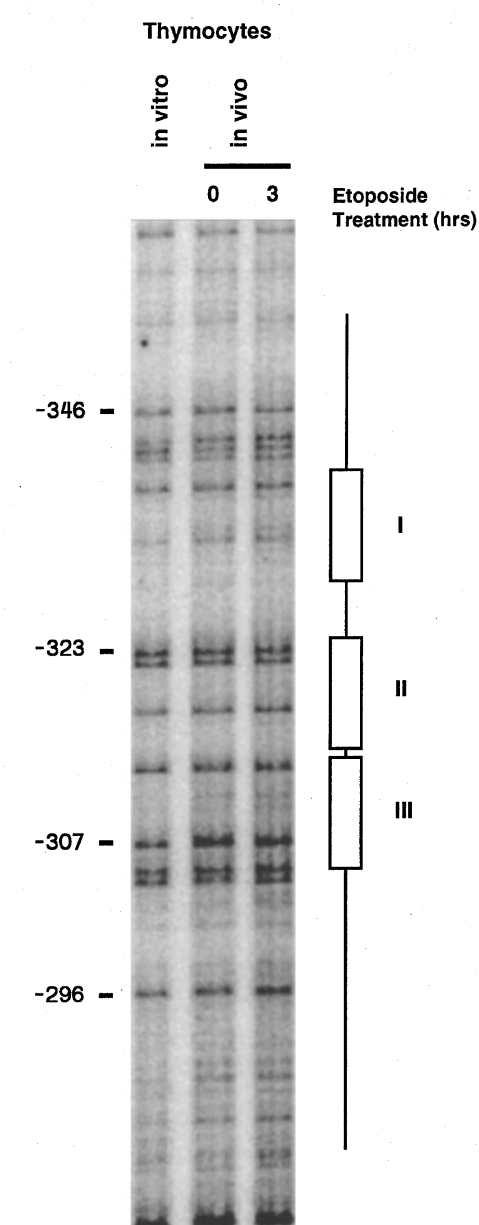

Figure 5 The transcriptional activity of the murine bax promoter is not enhanced by $p 53$. (a) Sequence comparison between potential murine $p 53$ binding sites in the murine bax promoter and $p 53$ binding sequences of the p2 $1^{\text {Waf1 } 1}$, the human bax and the cyclin G gene. ${ }^{6,36,37}$ Mismatches to the p53 consensus sequence (on the top) are underlined. (b) Transient co-transfections of p53-deficient cell lines (Saos-2, Hela) with the murine bax promoter and wt or mutant p53 expression constructs. Similar results were obtained in transient transfections with the T-cell line EL-4 (data not shown). The mdm2 reporter was used as a positive control. (c) Analysis of in vivo protein occupation of the coding strand in the region between position -290 and -350 of the bax promoter by genomic DMS footprinting of etoposide-treated and untreated mouse thymocytes 
the protein in T-cells show accelerated cell death but cannot substitute for p53 deficiency in DNA damage-induced apoptosis. ${ }^{9}$ These findings suggested that Bax is not regulated by p53 in murine cells and that other downstream effectors are responsible for the action of p53. However, in another mouse model, where p53 induced apoptosis regulates tumor formation in choroid plexus epithelial cells initiated by targeted expression of a SV40 T-antigen fragment, Bax expression appeared to be dependent on the presence of p53. ${ }^{24}$ Moreover, the loss of Bax accelerated tumor formation in these animals considerably suggesting a regulation of Bax by p53 in promoting cell death of the choroid plexus tumor cells. ${ }^{24}$ Another example is given by a study that investigated the effects of Bax deficiency in fibroblasts expressing the $\mathrm{E} 1 \mathrm{~A}$ oncogene - a situation where apoptosis depends on p53. Here, the chemosensitivity of cells is mediated by Bax in a p53 dependent pathway. ${ }^{25}$

Thus, a number of different experimental systems have produced a controversy as to which extent and by what mechanism Bax is regulated by $\mathrm{p} 53$ in DNA damageinduced apoptosis. We wanted to clarify this question by analyzing the murine bax promoter. Our findings suggest that Sp1 and possibly Sp3 but also so far unidentified Ebox binding transcription factors play a pivotal role in regulating Bax transcription. However, we can show that in vivo after DNA damage when p53 is fully induced it does a

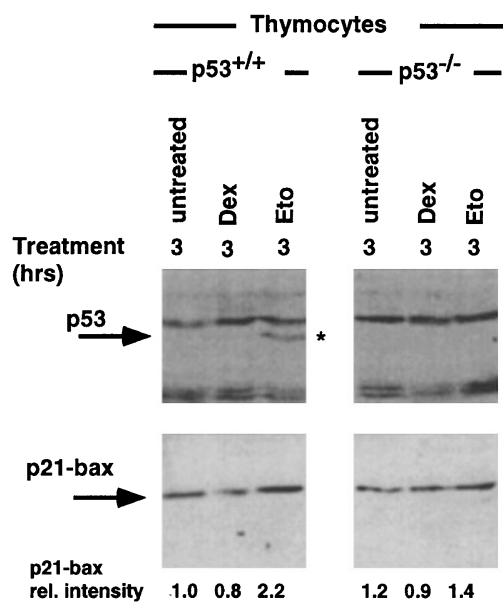

b

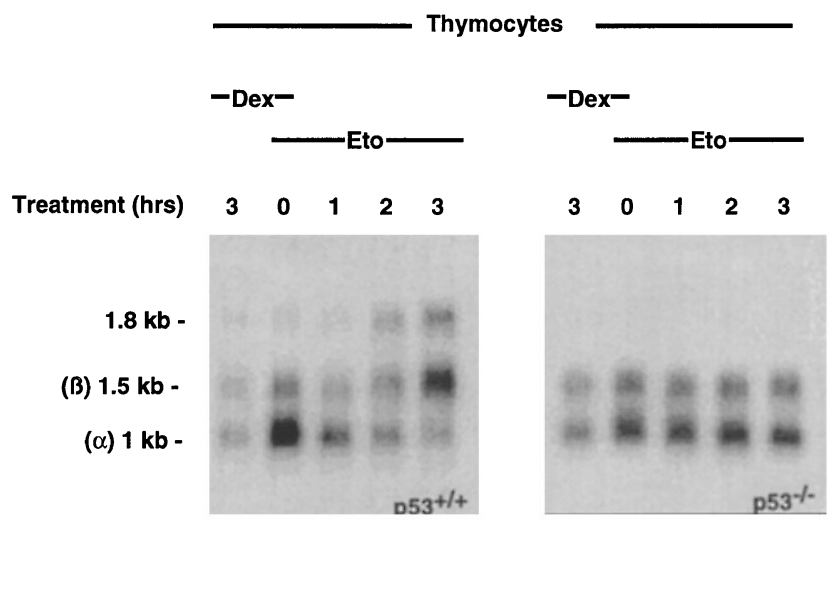

C

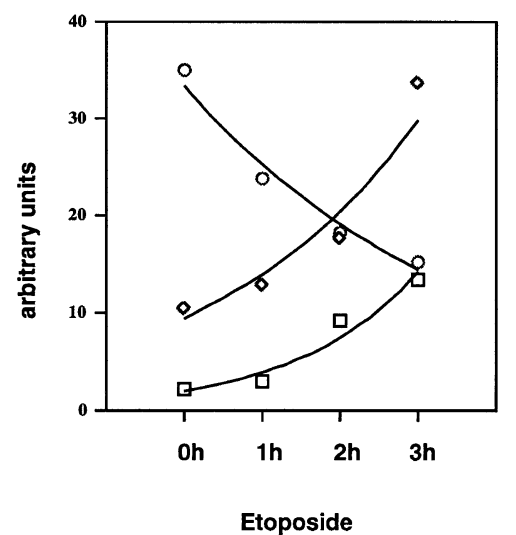

d

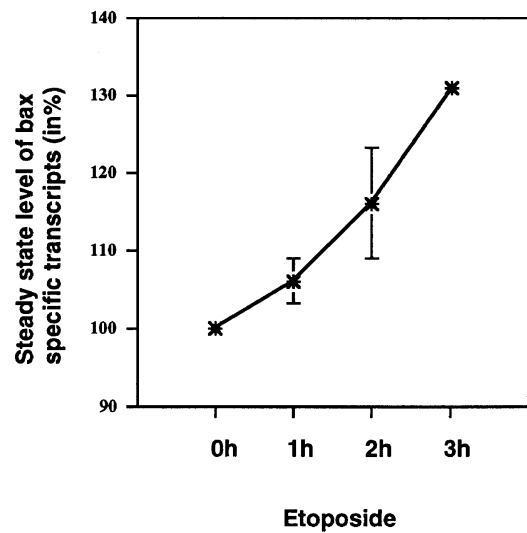

ㅁ bax $1.8 \mathrm{~kb}$

- bax $1.5 \mathrm{~kb}(B)$

$\circ$ bax $1.0 \mathrm{~kb}(\alpha)$

* bax message (total)

Figure 6 The p53-dependent upregulation of Bax protein correlates with a redistribution of the different bax mRNA species in murine thymocytes. Western (a) and Northern blot analysis (b) of p53 and bax-expression in wild-type and p53-deficient thymocytes in response to different apoptotic stimuli as indicated. The relative intensities of Bax protein expression was determined by scanning autoradiographies. Equal protein loading was checked by Ponceau staining of the membrane. The steady state level of bax mRNA expression was measured by determining emitted radiation from the hybridized Northern membranes on a Fuji Bio-Imager with subsequent analysis by the AIDA software (Raytest, Germany). Equal loading was controlled by staining the gel for ribosomal RNA. (c) Phosphoimager quantification of the different bax mRNA subspecies is given in arbitrary units. (d) Increase in total amount of bax mRNA signals obtained by Bio-Imager quantification of Northern blots. The bax mRNA level in untreated thymocytes $(0 \mathrm{~h})$ was at $100 \%$. The transcripts denoted $\alpha$ and $\beta$ can encode the p 21 bax $\alpha$ protein or the $\mathrm{p} 24$ bax $\beta$ protein, respectively ${ }^{28}$ 
not bind to sequences within the bax promoter and, in addition, reporter gene constructs comprising up to $6.5 \mathrm{~kb}$ of the murine bax promotor sequence did not respond to p53. We cannot rule out that outside the $6.5 \mathrm{~kb}$ upstream of the bax initiator ATG there may be $p 53$ binding sites but at least the sites that are in the same position as in the human promoter clearly do not contribute to the regulation of Bax expression by p53. This would represent a fundamental difference between the regulation of the murine and the human bax promoter. ${ }^{6}$

In the murine system, we observe after DNA damage a differential regulation of at least three different Bax mRNA subspecies. One of them is the $1.5 \mathrm{~kb}$ transcript which is upregulated upon DNA damage but is not translated into the predicted $24 \mathrm{kD}$ and $4.5 \mathrm{kD}$ bax proteins. The other is the $1.0 \mathrm{~kb}$ bax mRNA subspecies which gives rise to the p21 bax $\alpha$ protein. According to the observed alterations of steady state mRNA levels a downregulation of the $21 \mathrm{kD}$ Bax $\alpha$ protein and upregulation of a $24 \mathrm{kD} \beta$ form would be expected after DNA damage. However, this was not reflected on Western analysis, in contrast, only the $21 \mathrm{kD}$ Bax $\alpha$ form is detected at appreciable levels after DNA damage. This suggests a regulation of Bax expression at the post-transcriptional level possibly affecting the translation efficiency of the $1.0 \mathrm{~kb}$ bax mRNA subspecies counteracting the decreasing steady state levels after DNA damage. At the same time, no protein product corresponding to the increased steady state levels of the $1.5 \mathrm{~kb}$ the bax mRNA can be observed suggesting that the translation of this message is blocked. Moreover, the coding potential of the third $1.8 \mathrm{~kb}$ mRNA is unknown and remains to be determined. It is therefore very likely that although all mRNA subtypes are present and regulated during DNA damage, only the p21 kD Bax $\alpha$ protein is being produced at detectable levels.

Interestingly, in primary murine thymocytes the $21 \mathrm{kD}$ Bax $\alpha$ protein appears to be expressed also when p53 is absent. Moreover, thymocytes stimulated to undergo apoptosis at a response to dexamethasone express similar levels of $21 \mathrm{kD}$ Bax $\alpha$ protein regardless of p53 status. The fact that in the absence or in the presence of p53 steady state levels of both bax $1.0 \mathrm{~kb}$ and $1.5 \mathrm{~kb}$ mRNA subspecies decrease upon dexamethasone treatment but Bax protein remains unchanged at levels indistinguishable from untreated cells is again an indicator for the existence of regulatory mechanisms at the translational level.

As a conclusion, we present evidence that argues against p53 as a direct upstream regulator of Bax in DNA damage-induced apoptosis or in steroid induced apoptosis in murine cells. We believe it is safe to conclude from our data that the low level of alteration of Bax protein seen in DNA damage-induced death in thymocytes does not occur by a mechanism of transcriptional transactivation of the Bax promoter via p53 but rather involves a post-transcriptional mechanism possibly affecting the translation efficiency of a particular bax mRNA subtype. Our findings contrast strongly with those on p53 dependent regulation of bax expression in human cells. ${ }^{6}$ However, this may not necessarily be a contradiction but rather a reflection of different regulatory pathways that have developed in different species with the same or similar outcome. Although we have used fibroblasts and T-cells in our study and thus feel that our results reflect the situation of a variety of murine tissues, yet another mechanism of bax regulation that has still to be fully elucidated could prevail in neuronal cells where recent results link p53 and Bax in excitotoxin induced cell death. ${ }^{38}$

\section{Materials and Methods}

\section{Genomic footprinting}

For genomic in vivo footprinting, ${ }^{29}$ thymocytes from wild-type and p53 KO mice were isolated as described ${ }^{30}$ and NIH3T3 were grown to $70 \%$ confluency. For dimethyl sulfate footprinting the cells were treated with $0.2 \%$ dimethyl sulfate (DMS) for $2 \mathrm{~min}$. After DMS treatment, cells were washed once with warm medium and three times with cold PBS. DNA isolation was performed with DNAzol (Gibco BRL). Piperidine cleavage of the DNA was performed for $30 \mathrm{~min}$ at $90^{\circ} \mathrm{C}$ with $10 \%$ piperidine. The reaction was stopped by addition of $1 / 10$ reaction volume of $3 \mathrm{M} \mathrm{NaCl} \mathrm{pH} 5.2$ and immediate ethanol precipitation. Residual traces of piperidine were removed by lyophilisation, transfer of the DNA into a new eppendorf tube and two additional ethanol precipitations. The DNA was resuspended in TE $\mathrm{pH} 8.0$ and $3 \mu \mathrm{g}$ of genomic DNA were used for ligation-mediated PCR (LMPCR) as described. $^{31}$ The Stoffel fragment of Taq polymerase (Perkin Elmer) was used instead of the native enzyme. Samples were phenol extracted and ethanol precipitated after primer extension with ${ }^{32} \mathrm{P}$ labeled primers. The following oligonucleotides were used as primers: For the analysis of E-boxes and Sp1-binding sites: 1st primer, $\mathrm{T}_{\mathrm{m}}=54^{\circ} \mathrm{C}, 5^{\prime}$-(ATGAATCTATGGGAAGAAGA); 2nd primer, $\mathrm{T}_{\mathrm{m}}=74^{\circ} \mathrm{C}$, $5^{\prime}$-(GAAACAACCAACTCTGGGCATCAGT); 3rd primer, $\mathrm{T}_{\mathrm{m}}=86^{\circ} \mathrm{C}, 5^{\prime}$ (TCTGGGCATCAGTTCGGATTAAGGTCGAT).

For the analysis of p53-binding sites: 1 st primer, $T_{m}=56^{\circ} \mathrm{C}, 5^{\prime}$ (CGGGTACTAAATGAACGCA); 2nd primer, $\mathrm{T}_{\mathrm{m}}=72^{\circ} \mathrm{C}, 5^{\prime}$-(GACCTTAATCCGAACTGATGCCCAG); 3rd primer, $\mathrm{T}_{\mathrm{m}}=90^{\circ} \mathrm{C}, 5^{\prime}$-(GATGCCCAGAGTTGGTTGTTTCCCCCC).

\section{Cell culture and transient transfection assays}

NIH3T3, Saos-2 and HeLa cells were cultured in Dulbecco's modified Eagle medium (DMEM) with $10 \%$ fetal calf serum. All cell types were transfected with $1-3 \mu \mathrm{g}$ of DNA per $3 \mathrm{~cm}$ dish by the DEAE dextran technique and luciferase activities were determined as described. ${ }^{31}$ Luciferase assays and FACS analyses were performed as described. ${ }^{31}$ EL4 T-lymphocytes were cultured in RPMI medium with $10 \%$ fetal calf serum and transfected by electroporation. Cells were pulsed at $220 \mathrm{~V} / 950 \mu \mathrm{F}$ with $10 \mu \mathrm{g}$ DNA in a total volume of $200 \mu \mathrm{l}$ and harvested for luciferase activity $24 \mathrm{~h}$ after transfection. Thymocytes from wild-type and p53 KO-mice were isolated as previously described. $^{30}$ The isolated thymocytes were resuspended at $10^{6}$ cells $\times \mathrm{ml}^{-1}$ and treated with $2 \mu \mathrm{M}$ dexamethasone (Sigma) or $50 \mu \mathrm{M}$ etoposide (Sigma) respectively. To inhibit the synthesis of new mRNA $1 \mu \mathrm{g} / \mathrm{ml}$ actinomycin D was applied and the cells were harvested after different periods of time.

\section{Sequence analysis and luciferase constructs}

DNA sequencing was performed by the dideoxynucleotide chaintermination method using T7 Sequencing Kit (Pharmacia). The reporter gene construct containing the mdm2 promoter was a generous gift from W. Deppert, Hamburg. The construct contains a 
$350 \mathrm{bp}$ Xhol, Hincll fragment of the human mdm2 intronic promoter, ligated into the pGL3 basic luciferase vector (Promega) digested with Xhol and Smal. The Bax-Luc constructs used are shown in Figure 3. Different fragments of the murine bax locus were isolated by restriction enzyme digest from a $14 \mathrm{~kb}$ subcloned (pBS3107) Bax genomic DNA phage clone ( $p F 2 / S R I)$ fragment and cloned into the $p G L 3$ basic vector (Promega). All cloned PCR-amplified fragments and deletion constructs were verified by DNA sequencing. The p53 WT and conformational mutant p53 $175 \mathrm{H}$ expression constructs were a generous gift from K. Römer (University of Saarland, Homburg) and are described. $^{27}$

\section{Start site mapping}

Primer extension analysis was performed using $0.6 \mathrm{ng}{ }^{32} \mathrm{P}$-labeled oligonucleotide. Primer annealing was performed in a $20 \mu \mathrm{l}$ reaction containing $25 \mu \mathrm{g}$ of total RNA (NIH3T3 or Thymocytes), $100 \mathrm{mM} \mathrm{NaCl}$,

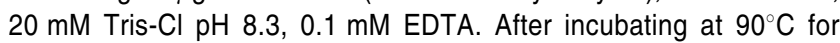
$3 \mathrm{~min}$, the reaction was transferred to a water bath at $68^{\circ} \mathrm{C}$ for $10 \mathrm{~min}$ and then slowly cooled to $42^{\circ} \mathrm{C}$. Eight $\mu \mathrm{l} 5 \times$ first-strand-buffer (Gibco/ BRL), $2 \mu \mathrm{l} 10 \mathrm{mM} \mathrm{dATP} / \mathrm{dCTP} / \mathrm{dGTP} / \mathrm{dTTP}, 4 \mu \mathrm{l} 0.1 \mathrm{M}$ DTT, $1 \mu \mathrm{l}$ RNAguard (Pharmacia) and $1 \mu \mathrm{l}$ Superscript reverse transcriptase (Gibco BRL) were added to a final volume of $40 \mu \mathrm{l}$. The reaction was incubated for $1 \mathrm{~h}$ at $42^{\circ} \mathrm{C}$ and was stopped by adding $2 \mu \mathrm{l}$ of $0.5 \mathrm{M}$ EDTA. Samples were digested with $1 \mathrm{U}$ RNaseA (Boehringer Mannheim), extracted with phenol-chloroform-isoamylalcohol, precipitated with ethanol and separated on a denaturing $6 \%$ polyacrylamide gel. 5'-RACE - PCR was performed as described in Frohmann. ${ }^{34}$ The following oligonucleotides were used as primers: Bax PE IV 5'-(TGCTCCCCGGACCCGTCCAT); Bax PE V 5'-(CCGCCGCTCCCAAGCTGCTC); Bax PE VI 5'-(GATCTGTTCAGAGCTGGTGG); 5'Race: 5'-(GACTCGAGTCGACATAGATTTTTTTTTTTTTTTTTTT); RaceBax I 5'-(GCTCCATATTGCTATCCAG); RaceBax II 5'-(AAGGTCAGCTCAGGTGTCTC).

\section{Electrophoretic mobility shift assays}

Nuclear extracts were prepared from exponentially growing NIH3T3 cells as described. ${ }^{32}$ Electrophoretic mobility shift assays (EMSA) were performed by incubating $1-2 \mu \mathrm{l}$ of nuclear extract with approximately 0.5 picomoles of radiolabeled probe as described previously. ${ }^{33}$ EMSA reactions were performed at room temperature for $15 \mathrm{~min}$ followed by gel electrophoresis using $4 \%$ polyacrylamide gels. Supershifts were carried out by preincubating EMSA reactions on ice for 20 min with $2 \mu$ of the indicated antibodies prior to addition of the radiolabeled probe. Sp1 and Sp3 antibodies ${ }^{22}$ were obtained from Dr. G. Suske (IMT, Marburg, Germany). Competition with cold probes were performed by addition of the unlabeled competitor oligonucleotide $2 \mathrm{~min}$ before the radiolabeled probe. The following oligonucleotides were used as probes and/or competitors: GT-box 5'(AGCTTCCGTT-GGGGTGTGGCTTCACGTCGA) and 5'(TCGACGTGAAGCCACAC-CCCAACGGAAGCT); Sp1/l 5'-(GAAATAATGGGGGCGGGGGGG-GAAACAA) and $5^{\prime}$ (GTTGTTTCCCCCCCCGCCCCCATTATTT); Sp1/II 5'(GTACCCGCGGCCCCGCCCCTGCAGCGAG) and 5'-(GCTCGCTGCAGGGGCGGGGCCGCGGGTA); Sp1/III 5'-(GAGTCCTGCGGGGCGGAGGCCATGTTGC) and 5'-(GGCAACATGGCCTCCGCCCCGCAGGACT); unspec. 5'-(GAATAAAGTTTTACTGATTTTTGAGACA) and 5'-(GTGTCTCAAAAATCAGTAAA-ACTTTATT).

\section{RNA and immunoblotting}

Preparation of RNA and Northern blotting was performed according to described procedures. ${ }^{34,35}$ Equal RNA loading was routinely controlled by ethidium-bromide staining. Protein extracts from etoposide or dexamethasone treated or untreated thymocytes were loaded and separated on SDS-PAGE, transferred onto membranes and the Bax and $\mathrm{p} 53$ protein were detected with an anti Bax rabbit antiserum (UBI, Cat\# 06-499) or anti-p53 mouse antiserum (PAB 240, gift from W. Deppert, Hamburg, Germany) using anti-rabbit Ig or anti-mouse Ig coupled to horse radish peroxidase. The enzymatic activity was detected using an ECL kit (Amersham) according to the specifications of the manufacturer. Equal and homogeneous transfer of proteins from the gel to membranes was routinely controlled by Ponceau $S$ staining of the membrane.

\section{Acknowledgements}

We thank W. Deppert, Hamburg, for the intact and mutant hmdm2luciferase reporter gene constructs, K. Roemer for expression constructs of wild-type and mutant p53 and C. Borner for Bax antibodies. This work was supported by a grant from the Deutsche Forschungsgemeinschaft (Mo 435/10-1) and the 'Fond der chemischen Industrie'.

\section{References}

1. Kroemer G (1997) The proto-oncogene Bcl-2 and its role in regulating apoptosis. Nature Med. 3: 614-620

2. Möröy T andZörnigM(1997) Regulators of life and death: the bcl-2 gene family. J. Cell Phys. Biochem. 6: 312-336

3. Reed JC (1997) Double identity for proteins of the Bcl-2 family. Nature 387: $773-$ 776

4. Strasser A, Huang D and Vaux DL (1997) The role of the bcl-2/ced-9 gene family in cancer and general implications of defects in cell death control for tumorigenesis and resistance to chemotherapy. Biochim. Biophys. Acta 1333: F151-F178

5. Kitada S, Krajewski S, Myashita T, Krajewska M and Reed JC (1996) Gamma radiation induces upregulation of Bax protein and apoptosis in radiosensitive cells in vivo. Oncogene 12: 187-192

6. Miyashita T and Reed JC (1995) Tumor suppressor p53 is a direct transcriptional activator of the human bax gene. Cell 80: 293-299

7. Knudson CM, Tung KS, Tourtellotte WG, Brown GA and Korsmeyer SJ (1995) Bax-deficient mice with lymphoid hyperplasia and male germ cell death. Science 270: $96-99$

8. Brady HJ, Gil-Gomez G, Kirberg J and Berns AJ (1996) Bax alpha perturbs T cell development and affects cell cycle entry of T cells. EMBO J. 15: 6991-7001

9. Brady HJ, Salomons GS, Bobeldijk RC and Berns AJ (1996) T cells from bax alpha transgenic mice show accelerated apoptosis in response to stimuli but do not show restored DNA damage-induced cell death in the absence of $p 53$. EMBO J. $15: 1221-1230$

10. Chen X, Ko LJ, Jayaraman L and Prives C (1996) p53 levels, functional domains, and DNA damage determine the extent of the apoptotic response of tumor cells. Genes Dev. 10: 2438-2451

11. Donehower LA (1996) The p53-deficient mouse: a model for basic and applied cancer. Semin. Cancer Biol. 7: 269-278

12. Gottlieb E and Oren M (1996) p53 in growth control and neoplasia. Biochem. Biophys. Acta 1287: 77-102

13. Ko LJ and Prives C (1996) p53: puzzle and paradigm. Genes \& Dev. 10: 1054 1072

14. Levine A (1993) The tumor suppressor genes. Ann. Rev. Biochem. 62: 623-651

15. El-Deiry WS, Tokino T, Velculescu VE, Levy DB, Parsons R, Trent JM, Lin D, Mercer WE, Kinzler KW and Vogelstein B (1993) WAF1, a potential mediator of p53 tumor suppression. Cell 75: 817-825 
16. HarperJW, Adami GR, Wie N, Keyomarsi Kand Elledge SJ (1993) The p21 CDKinteracting protein $\mathrm{Cip} 1$ is a potent inhibitor of $\mathrm{G} 1$ cyclin dependent kinases. Cell 75: $805-816$

17. Xiong Y, Hannon GJ, Zhang D, Casso D, Kobayashi Rand Beach D (1993) p21 is a universal inhibitor of cyclin kinases. Nature 366: 701-704

18. Attardi LD, Lowe SW, Brugarolas J and Jacks T (1996) Transcriptional activation by $p 53$, but not induction of the $\mathrm{p} 21$ gene, is essential for oncogene-mediated apoptosis. EMBO J. 15: 3693-3701

19. Evan GE, Brown L, Whyte M and Harrington E (1995) Apoptosis and the cell cycle. Curr. Opin. Cell Biol. 7: 825-834

20. Zörnig M, Hueber A-O and Evan G (1999) Programmed cell death and senescence. In press

21. Grimes HL, Gilks CB, Chan TO, Porter S and Tsichlis PN (1996) The Gfi-1 protooncoprotein represses Bax expression and inhibits T-cell death. Proc. Natl. Acad. Sci. USA 93: 14569-14573

22. Dennig J, Hagen G, Beato Mand Suske G (1995) Members of the Sptranscription factor family control transcription from the uteroglobin promoter. J. Biol. Chem. 270: $12737-12744$

23. Desbarats L, Gaubatz S and Eilers M (1996) Discrimination between different $E$ box-binding proteins at an endogenous target gene of c-myc. Genes Dev. 10: $447-460$

24. Yin C, Knudson CM, Korsmeyer SJ and Van Dyke T (1997) Bax suppresses tumorigenesis and stimulates apoptosis in vivo. Nature 385: 637-640

25. McCurrach ME, Connor TMF, Knudson CM, Korsmeyer SJ and Lowe SW (1997) Bax-deficiency promotes drug resistance and oncogenic transformation by attenuating p53-dependent apoptosis. Proc. Natl. Acad. Sci. USA 94: 23452349

26. Zauberman A, Flusberg D, HauptY, Barak Y and Oren M (1995) A functional p53responsive intronic promoter is contained within the human $\mathrm{mdm} 2$ gene. Nuc. Acids Res. 23: 2584-2592

27. StählerFand RömerK (1998) Mutantp53 can provoke apoptosis in p53-deficient Hep3B cells with delayed kinetics relative to wild-type p53. Oncogene 17:35073512
28. Oltvai ZN, Milliman CL and Korsmeyer SJ (1993) Bcl-2 heterodimerizes in vivo with a conserved homolog, Bax, that accelerates programmed cell death. Cell 74: $609-619$

29. Pfeifer GP, Steigerwald SD, Mueller PR, Wold B and Riggs AD (1989) Genomic sequencing and methylation analysis by ligation mediated PCR. Science 246 : $810-813$

30. Möröy T, Grzeschiczek A, Petzold S and Hartmann KU (1993) Expression of a pim- 1 transgene accelerates lymphoproliferation and inhibits apoptosis in Ipr/lpr mice. Proc. Natl. Acad. Sci. USA 90: 10734-10738

31. Lucibello FC, Truss M, Zwicker J, Ehlert F, Beato M and Müller R (1995) Periodic cdc25C transcription is mediated by a novel cell cycle-regulated repressor element (CDE). EMBO J. 14: 132-142

32. Dignam JD, Martin PL, Shastry BS and Roeder RG (1993) Eukaryotic gene transcription with purified components. Methods Enzymol. 101: 582-598

33. Engeland K, Andrews NC and Mathey-Prevot B (1995) Multiple proteins interact with the nuclear inhibitory repressor element in the human interleukin-3 promoter. J. Biol. Chem. 270: 24572-24579

34. Frohmann MA, Dush MK and Martin GR (1988) Rapid production of full-length cDNAs from rare transcripts: Amplification using a single gene-specific oligonucleotide primer. Proc. Natl. Acad. Sci. USA 85: 8992-9002

35. Sambrook J, Fritsch EF and Maniatis T (1989) Molecular Cloning. In: Nolan C, Ford N, Ferguson M. (eds.). A laboratory manual, second edition chapter 7.3. CSH-Laboratory Press

36. Okamoto $\mathrm{K}$ and Beach $\mathrm{D}$ (1994) Cyclin $\mathrm{G}$ is a transcriptional target of the $\mathrm{p} 53$ tumor suppressor protein. EMBO J. 13: 4816-4822

37. El-Deiry WS, Kern SE, Pietenpol JA, Kinzler KW and Vogelstein B (1992) Definition of a consensus binding site for p53. Nat. Genet. 1: 45-49

38. Xiang $\mathrm{H}$, Kinoshita $\mathrm{Y}$, Knudson $\mathrm{CM}$, Korsmeyer SJ, Schwartzkroin PA and Morrison RS (1998) Bax involvement in p53-mediated neuronal cell death. J. Neurosci. 18: 1363-1373 